\title{
REGINA BIOLOGY CLASS STUDIES NESTING AND COURTSHIP BEHAVIOUR OF SAGE GROUSE
}

Photographs by John Stronski, Regina

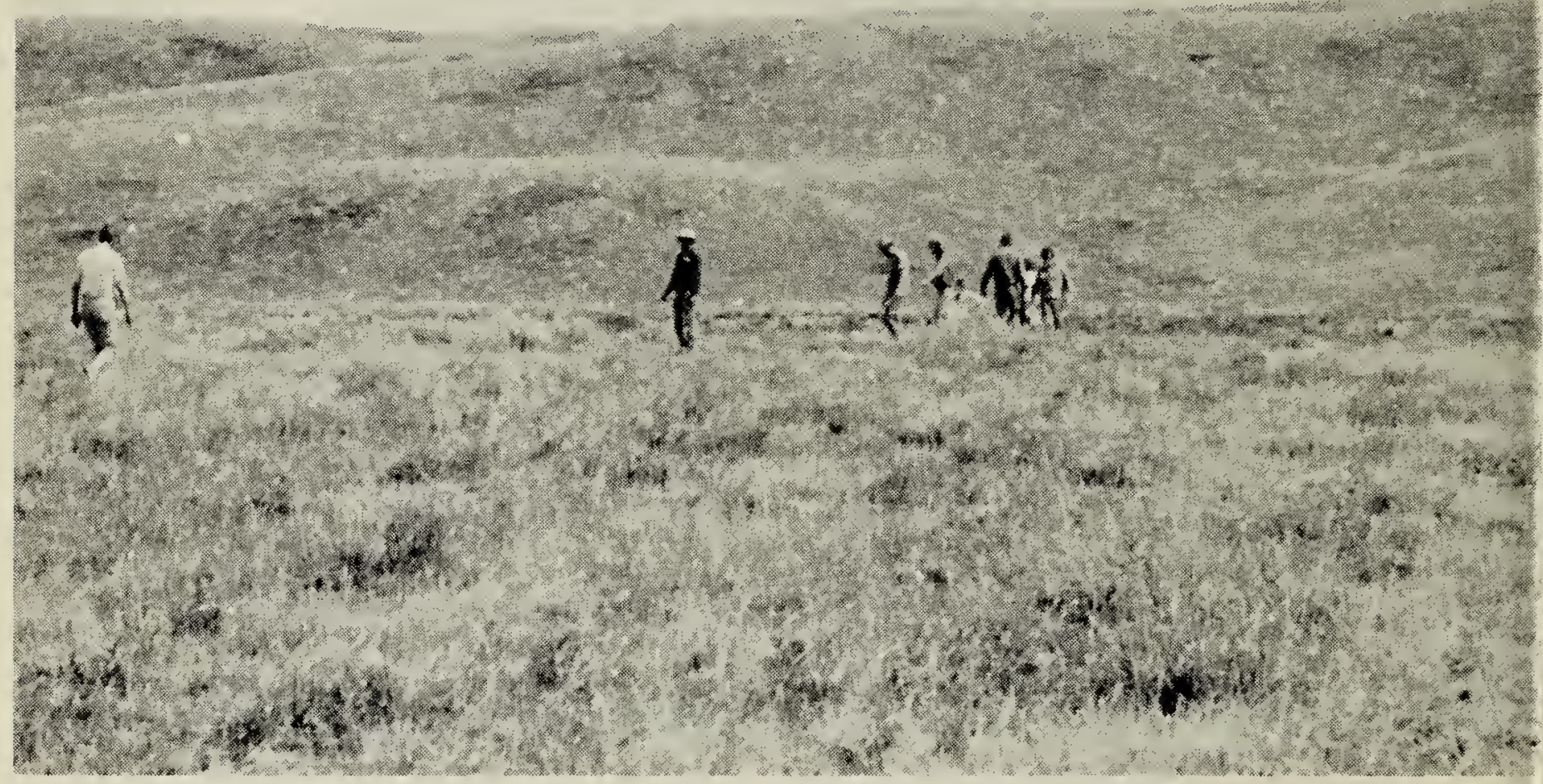

Sage Grouse nest search in sagebrush-grassland

habitat in Frenchman River valley, May 11, 1971.

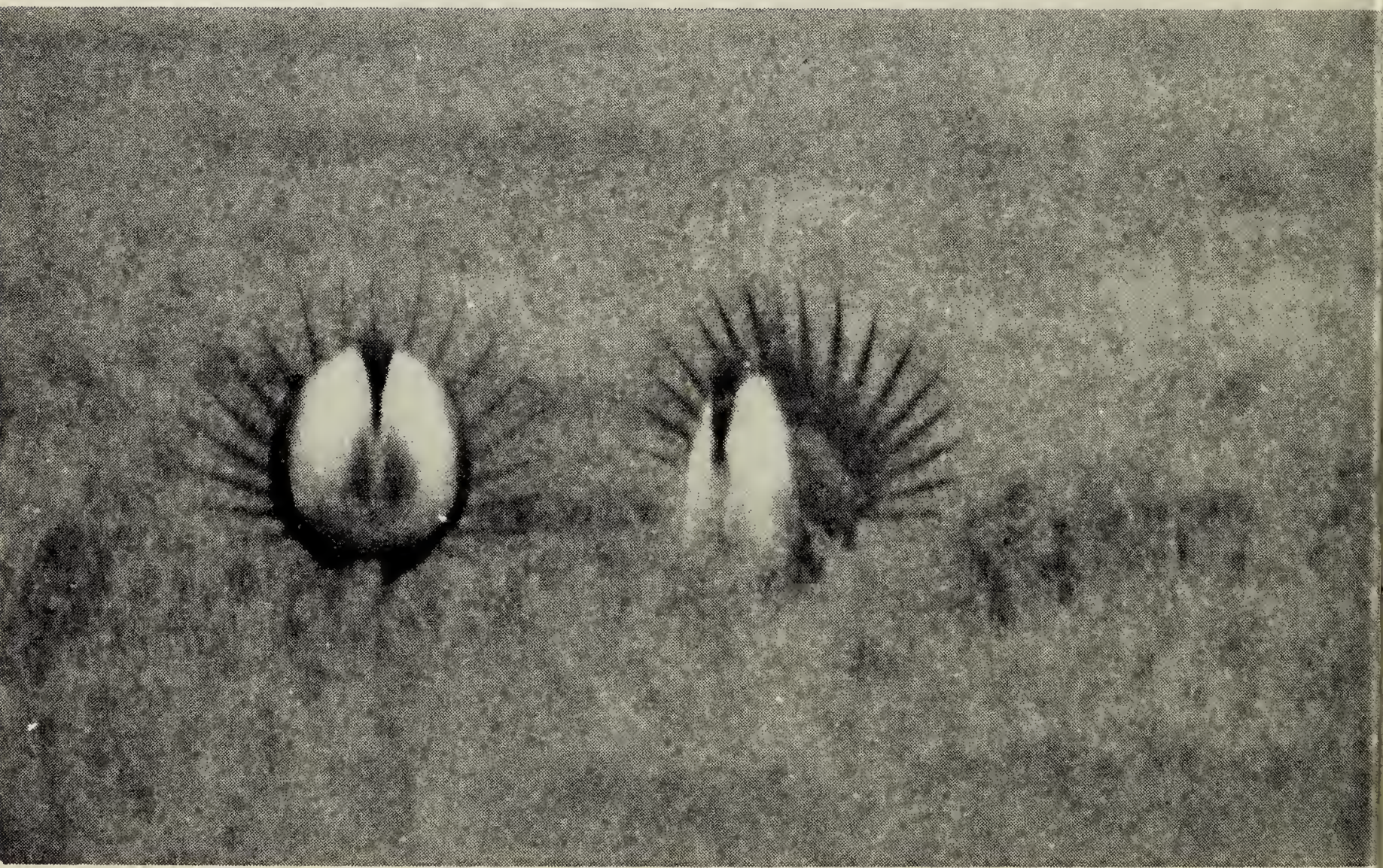

Two adult Sage Grouse cocks displaying at adjacent boundaries of their territories. 


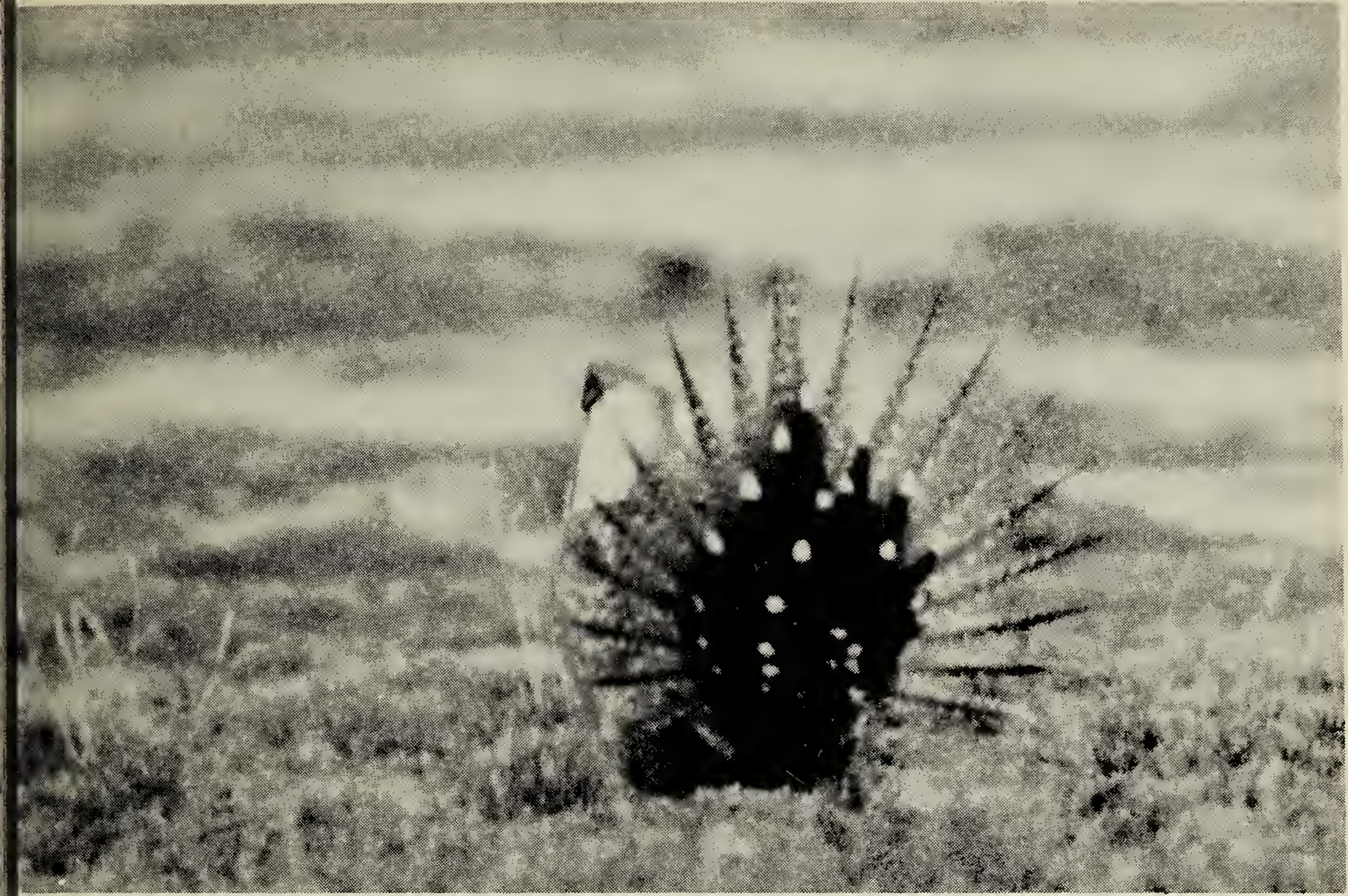

Rear view of fan-tailed displaying cock fage Grouse, May 11, 1971.

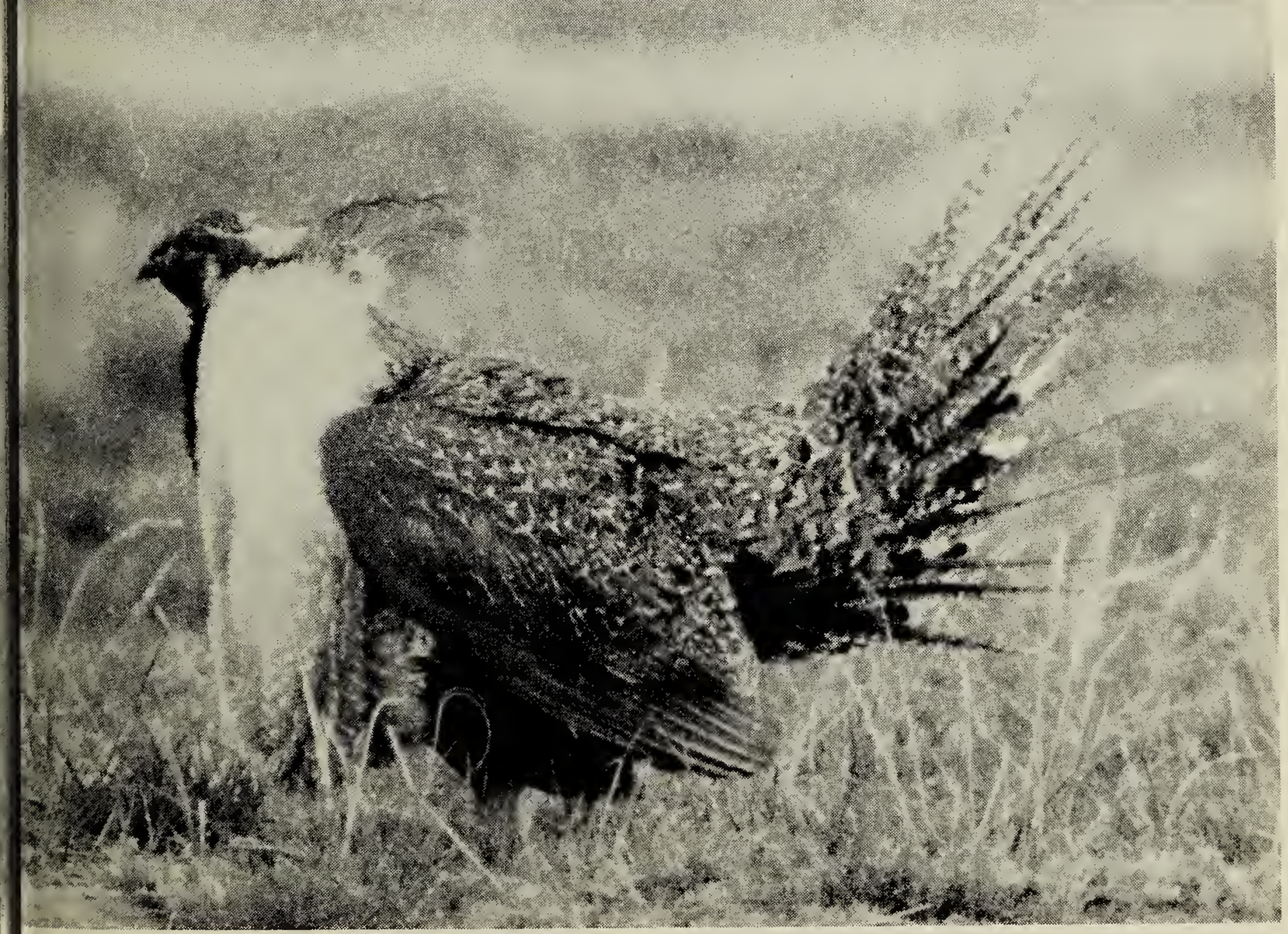

Lateral view of displaying cock Sage Grouse showing distended oesophageal sac and erect filoplumes on head. Note drooping wings. 